\title{
Making the Links: Equity Pedagogy, Pre-Service Teacher Dispositions and Technology for Inclusion
}

\author{
Vashti Singh \\ The University of the Trinidad and Tobago \\ Trinidad and Tobago
}

\begin{abstract}
This study attempts to examine current approaches to equity pedagogy and to identify the kinds of teacher dispositions necessary for developing culturally responsive teachers who can effectively use technology in diverse classrooms. In this study, particular attention is given to an analysis of six (6) teacher dispositions explicit in focus group overview data (4 focus groups of 5 members each) of twenty (20) pre-service teachers (Years 3 and 4) in the Social Studies Programme, Bachelor of Education Degree at The University of Trinidad and Tobago. The six (6) dispositions are (i) a meaningful philosophy of education, (ii) commitment, (iiii) intercultural sensitivity, (iv) social justice and equity, (v) communication and (vi) reflection. Pre-service teachers can relate the six (6) dispositions to three (3) domains of Knowledge - Knowledge of the Self, Knowledge of the Other, and Knowledge of the Community - in the context of assessing best equitable practices to become both culturally responsive and technologically proficient. The study demonstrates how a profound relationship between equity pedagogy and teacher dispositions provides a foundation for pre-service teaches to use technology in a culturally relevant manner and thus confront the global demands for 21st century inclusive education.
\end{abstract}

\section{Introduction}

The Dakar Framework for Action endorsed a World Declaration on Education for All (EFA) in 2000. The goal was inclusive education [20]. Ninety-two (92) governments and twenty-five (25) international organizations subscribed to the view that every child has unique characteristics, interests, and abilities and "those with special education needs must have access to regular schools which should accommodate them with a child-centered pedagogy capable of meeting those needs" ( The Salamanca Statement [19]. The Government of Trinidad and Tobago subscribes to UNESCO'S definition of inclusion as: "A process of addressing and responding to the diversity of needs of all learners through increasing participation in learning, cultures and communities and reducing exclusion within and from education" [18]. The Government identified that the process of inclusion can be profilerated if teachers understand that the role of technology in learning surpasses the issue of accessibility to embrace equitable use of technology in the learning process [17]. In this regard, the Bachelor of Teacher Education Programme at the University of Trinidad and Tobago (UTT) has emphasized that teachers need to be culturally responsive - able to relate to diverse cultures with the knowledge, skills and dispositions to better provide equity in technology driven classrooms where all children can be empowered to learn.

\section{Literature Review}

In the literature review, the researcher has sketched the integration of equity pedagogy and teacher dispositions that can support pre-service teachers in setting the stage for equity in the use of technology to promote inclusion.

\subsection{Equity Pedagogy}

Equity pedagogy exists when teachers modify their teaching in ways that bring about academic achievement of students from diverse racial, ethnic, cultural, gender and social class groups [2]. Differentiation is known as an approach to teaching in which teachers proactively modify curricula, teaching methods, resources, learning activities, and student products - to meet the diverse needs of individual students and small groups of students to maximize the learning opportunity for each student in a classroom [3]. Throughout the literature of the school reform movement on "Education for All" is an appeal for teachers to adjust curriculum materials and the necessary support to afford each student equity of access to high-quality learning [16].

Of major significance, equity pedagogy requires a shift in the power relationship between "teachers and students" if students from marginalized and complex backgrounds are expected to construct their own 
interpretations of reality, to generate knowledge and to offer multiple solutions for creating a just and democratic society. The classroom is a meeting ground of cultures where the "worlds of the students" ought to connect with the "worldview of schools and teachers." According to Gay, culturally responsive teachers use the "cultural knowledge, prior experiences, frames of references, and performance styles of ethnically diverse students to make learning encounters more relevant to and effective for them" [8]. Teachers must therefore develop cultural competence to collaborate with parents, families and communities; and learn how the cultural background of students impact upon their learning.

Clearly, the commitment to equity pedagogy raises serious concerns about pre-service teacher dispositions to work effectively with student populations that are becoming increasingly diverse.

\subsection{Dispositions}

The National Council for the Accreditation of Teacher Education (NATE) has defined teacher dispositions as: "The values, commitments and professional ethics that influence behaviours used toward students, families, colleagues, and communities and affect student learning, motivation and development as well as the educators own professional growth. Dispositions are guided by beliefs and attitudes related to values such as caring, fairness, honesty, responsibility and social justice” [12]. Dispositional factors, then, may determine prospective teachers' readiness (or lack thereof) [7] to learn from their intercultural and educational experiences in diverse classrooms.

Having conducted a three (3) year action research study, Bell and Thomas [4] indicated that the major barrier to any diversity professional development experience is teacher disposition regarding diversity. Teachers who encountered issues with race, social class, gender and learning styles found it difficult to understand how their dispositions toward diversity impacted upon student learning. Allard and Santoro underscored the need for pre-service teachers to: "interrogate their assumptions about class and culture and how these are played out in their pedagogical relationships with students” [1]. Research on equity pedagogy and teacher dispositions (worldviews) revealed that pre-service teachers' perceptions of themselves may influence how they perceive others with cultural experiences different from their own [11]. The mismatch between worldviews frequently lead teachers to view children of diverse backgrounds as children with deficits as learners.
In recent years, educators have focused on broadening the pedagogical skill centred view of teaching and learning in diverse classrooms to include a more dispositional view [15]. Since dispositions are guided by the moral and ethical dimensions of teaching; in the long dispositions may be seen as more important than skills.

Teacher education programs have a responsibility to develop in pre-service teachers the kinds of dispositions that would promote equity pedagogy in their diverse classrooms toward the greater goal of inclusion.

\section{Background to the Study}

Founded in 2006, the School for Studies in Learning, Cognition and Education (SSLCE) UTT, marked a significant shift from in-service diploma training to pre-service degree training for all teachers entering elementary and secondary schools. One prime objective is teacher quality for inclusion. Trinidad and Tobago's population comprises of: Africans (43\%), East Indians (36\%), White (1\%), Chinese (1\%), Lebanese Syrian (1\%), many of whom are racially and culturally Mixed (17\%). Furthermore, students belonging to different racial and ethnic groups in both denominational and government schools exhibit a range of learning abilities. The Social Studies Programme of SSLCE aims to provide pre-service teachers with an in-depth focus on equity pedagogy for inclusion open to the cultivation of multi-cultural dispositions that support it.

\section{Methodology}

The methodology employed in this study conforms to the qualitative research tradition in education. Focus group interviews and content analysis were carried out to obtain relevant information on equity pedagogy, dispositions and inclusion in pre-service teacher education.

\subsection{Participants}

The participants consisted of twenty (20) senior pre-service teachers (Years $3 \& 4$ ) enrolled in the Social Studies Programme at SSLCE. All the selected pre-service teachers have completed Practicum Courses which facilitated field teaching at either elementary or secondary schools according to their level of specialization. The Pre-Service Practicum Courses are aligned to the theoretical based ideas on teacher education. Having taught Social Studies/Practicum Courses to the pre-service 
teachers over one semester (12 weeks), the author recognized the majority of them have consolidated their opinions and beliefs about teaching in diverse classrooms. When this occurs, teacher candidates are seen as developing "the dispositions to teach" [5].

\section{The Research Question}

The study focused on one question: What kinds of dispositions do you believe are important for preservice teachers to practise equity pedagogy in diverse classrooms?

\section{The Discussion Guide}

Based on the theoretical framework of the study, the author elicited pre-service teachers' views and ideas about:

(i) EFA in Trinidad and Tobago (multicultural diversity issues).

(ii) Equity pedagogy (diverse classrooms, differentiated instruction, culturally competent teachers).

(iii) Teacher dispositions (definitions, dispositions for diversity, pre-service teachers' readiness).

(iv) Inclusion (integration of equity pedagogy and dispositions).

The flexible format of this discussion guide allowed the author to explore, probe and ask pertinent questions.

\section{Data Collection and Analysis}

Focus group interviews were used as a primary qualitative data gathering technique. The sample of twenty (20) pre-service teachers (10 males, 10 females) were divided in four (4) groups of five (5) students each: 2 Africans, 2 East Indians and 1 student of Mixed descent. The focus group must consist of representative members of the larger population. The author's objective was to gather "high quality data" in a social context where participants considered their own views in the context of the views of others. Each interview session lasted 30 minutes.

Interviews were recorded on audiotape and thereafter transcribed to form a written record. The author conducted a content analysis of the data derived from the four (4) focus groups. The analysis aimed to delineate trends and patterns that reappear within a single focus group or among the various focus groups.

\section{Findings}

From the data analysis, participants identified the following six (6) pre-service teacher dispositions which are actually manifested in their response to equity pedagogy and inclusion in real-life classrooms.

\subsection{A meaningful philosophy of education}

Overall the 4 focus groups felt that an integral disposition for equity pedagogy in diverse classrooms concerns their personal philosophy of education and vision. For example, many participants articulated that "all children can learn" and sought to build on this positive assumption. From their perspective, education involves a process of discovering and cultivating the unique capabilities, talents and interests that each child possesses. Education is thus a means of moving beyond the school and understanding the homes and communities children exist in and investigating socio-cultural factors that impact upon them as individual learners.

\subsection{Commitment}

A majority of participants from 3 focus groups understood that the belief "all children can learn" inevitably extends to a disposition of commitment towards an "ideal learning community." This kind of community only becomes possible when children of different gender, race and ethnic background have equal status in interactions and equal responsibility to work together and achieve learning outcomes. Thus, participants identified the need for pre-service teachers to develop an unsaid commitment to give each group, and more specifically, each child, space and voice. To guarantee equity pedagogy and inclusion, power has to be shared.

\subsection{Intercultural Sensitivity}

There was a general understanding among all group participants that pre-service teachers must become sensitive to community and cultural mores. They pointed out that children enter classrooms with identity problems, language deficiencies and different cultural codes; and hence pre-service teachers must not judge them by mainstream cultural measures but instead allow them to be themselves. Participants 
underlined that teachers need to demonstrate empathy, love and respect. According to one participant, "this may be the beginning point of learning which depends upon a genuine acceptance of the learner's private world.”

\subsection{Social Justice and Equity}

In each of the 4 focus groups, participants of all racial and ethnic backgrounds (African, East Indian and the Mixed Category) stated that pre-service teachers must have the determination to teach for social justice (fairness) and equity. Participants claimed that, in many instances, inequalities in diverse classrooms do not simply emerge from issues of race and ethnic identity, but are rooted in children's socio-cultural background. Accordingly, participants drew attention to individual variation in child development (social, emotional, cognitive, physical) and modification in teaching (objectives, resources, assessment strategies) to accommodate diverse talents and give each child fair and equitable access to learning opportunities.

\subsection{Communication}

The dispositions towards intercultural sensitivity and teaching for social justice led participants from 2 focus groups to question a dispositional focus on the cultural dimensions of communication both within and outside classrooms. They emphasized that pre-service teachers must structure interactions among culturally diverse students to facilitate powerful shared learning. Further, pre-service teachers must try to solve complex diversity issues in consultation with teachers, teacher educators, parents, community leaders and other relevant stakeholders in education. In fact, participants viewed communication with all stakeholders as they key to building a strong crosscultural learning community in classrooms.

\subsection{Reflection}

Participants from a single focus group reiterated that pre-service teachers must engage in reflection. They highlighted that reflective teachers can apply empirical, observational and analytical skills not only to the technical aspects of equity pedagogy but to the moral and ethical. Participants expressed a concern for pre-service teachers to rethink their own cultural perspective and interrogate the cultural assumptions underlying their beliefs, behaviours and expectations. One participant stated, "This kind of reflection can lead pre-service teachers to accept and become more sensitive to diverse cultures and the challenge of inclusive education.”

Based on the findings, the 4 focus groups held a consensus view that teacher education programmes must educate all teachers, those of majority or minority races/ethnic groups, to teach everybody's children. Teacher educators may find it beneficial to consider the extent to which their teacher education programs facilitate pre-service teachers with (i) the growth of a philosophy of education, (ii) the development of commitment to an ideal learning environment, (iii) increased intercultural sensitivity, (iv) teaching for social justice and equity, (v) opportunities to experience the cultural dimensions of communication, and (vi) training to reflect on both the technical and ethical aspects of teaching.

Pre-service teachers can relate the six (6) dispositions to three (3) domains of knowledge Knowledge of the Self, Knowledge of the Other and Knowledge of the Community - in the context of assessing best equitable practices to become culturally responsive and technologically proficient.

\section{Pre-Service Teacher Dispositions and Equitable use of Technology: Exploring Three Domains of Knowledge}

\subsection{The Self: A Meaningful Philosophy of Education and Commitment}

Pre-service teachers need to interpret what they encounter in diverse classrooms in philosophical terms pertaining to the "Self". To enhance their understanding of equity pedagogy, pre-service teachers must first know how historical forces and social institutions impact upon their own cultural identities, values and beliefs. A pertinent question for a pre-service teacher to consider is: "How do I feel about teaching students of a different race, class and gender? This approach may give a novice teacher a dispositional focus towards a philosophy of education that embraces diversity - all children can learn irrespective of their socio-cultural background and a commitment to the creation of an ideal learning community in classrooms. It is therefore imperative for pre-service teachers to address the "Self" through the use of technology in ways that increase their proficiency to build upon inclusion and a community of learners.

Education and modern technological systems now function in a global context. Trinidad and Tobago pre-service teachers can exchange views with peers in other countries to "better understand their own culture and the social, economic and political context that affects it" [6]. To collaborate with peers, pre- 
service teachers can utilize web-based technologies of email, chat, multi-media and internet conferencing. The Knowledge of the "Self" must have a positive impact on developing pre-service teachers' commitment to teach all children. Since each learner must be adequately served from within an ideal learning environment that embraces socio-cultural differences and equal participation, technology becomes an instrumental tool to convey each learner's unique ideas and interests [13]. Hence, during field-teaching pre-service teachers can use student telecollaborations, digital story-telling, virtual field-trips and CD-ROM based programmes for SelfPaced Learning to empower each learner.

\subsection{The Other: Intercultural Sensitivity and Social Justice and Equity}

Within an educational community, if the cultural background between the teacher and learner (the Other) becomes increasingly dissimilar, instructional mistakes will surface with greater frequency and severity [14]. In Trinidad and Tobago, some preservice teachers reside in race/ethnic and social class segregated areas where they have limited communication with other groups. Pre-service teachers in particular must be given opportunities to construct new knowledge about multicultural groups and develop dispositions of intercultural sensitivity and teaching for social justice and equity. A real issue is to train pre-service teachers to use technology for increased equity in learning outcomes.

Research has indicated that the implementation of information technologies in teacher education within a larger context of systemic reform can produce marked improvements in learning outcomes [9]. In 2010, the new People's Partnership Government (PPG) distributed a laptop computer to all Form One secondary school students to level the playing field between the "haves" and the "haves not." While this is a noteworthy initiative, it is necessary for preservice instructional technology courses to move beyond the question of access and literacy and explore issues of content, social justice and equity.

Computer medicated communication for on-line intercultural exchanges must facilitate a process through which pre-service teachers can become more sensitive to the complex cultural backgrounds of disadvantaged and "at risk" student populations of Trinidad and Tobago. Pre-service teachers can use virtual multi-cultural-based field experience (video production and multimedia development software) to record multicultural teaching (particularly construction of tasks to suit the developmental needs of students and initiatives to build on the strengths and aspirations of the dispossessed).
Using technology to teach for social justice and equity is essential to guarantee higher levels of learning outcomes and a reduction in achievement gaps between students of strikingly diverse cultural groups.

\subsection{The Community: Communication and Reflection}

To become equitable practitioners, pre-service teachers require dispositions for communication (inside and outside of classrooms) and reflection to understand that technology is not transformative on its own.

Effective use of technology in classrooms can cater for each student to become engaged in authentic complex tasks within a collaborative learning context. Through "engaged learning" students can interact with data and build knowledge collaborately. Pre-service teachers can devise a myriad of technology supported engaged learning projects through which students can solve real world problems, retrieve information from online resources and communicate with parents, teachers, other professionals and church leaders. For example, students can use Internet scanners and presentation software to plan and deliver speeches on Crime, Drug Abuse or Peer Pressure for a church seminar on Development of Youths. Thus, technology creates opportunities for pre-service teachers to act as colearners with students and other education stakeholders in the wider community to tackle issues of diversity and equity.

A reflective pre-service teacher does not only think about what is happening in a technology driven classroom but conducts research into his or her practice to make changes that will create a more ethical and learner-centered environment. A preservice teacher's "reflection" stated: "As far as pedagogy is concerned .... Different classrooms will have different needs and the simulation should be set up to meet those needs. I think it is a really good idea to receive feedback from the students to determine how a multimedia programme can be improved from year to year. The teacher must also reflect each year after completing the project, on what he or she felt went the way the teacher wanted, and what needs to be changed [10].

Some technology tools for reflection are blogs (reflective journal); Interactive Micro Blogging to record small but significant messages that capture "real life experiences" in the learning process; and Social Networking to receive feedback from people in the wider community.

Pre-service teachers must be cognizant of the fact that each domain of knowledge and their 
dispositional strengths overlap and are not separate. In addition, each diverse context demands different teacher dispositions and technological skills to observe equity in classroom practice.

\section{Future Research}

The Bachelor of Education Programme (UTT) will need to continue strengthening pre-service teacher dispositions through the infusion of technology with equity pedagogy concepts in field teaching. The author further recommends that teachers responsible for educational foundations and specialisation courses - incorporate meaningful learning experiences, dialogue and reflection on culturally responsive teaching and use of technology throughout the course context. Both practical training and theoretical groundwork must be integrated to address technology infusion and equity issues in public education. The three domains of knowledge can be used as a guide for pre-service teachers to monitor their own dispositions in relation to the Self (themselves), the Other (their students) and the Community, and thus develop equitable and technology rich teaching and learning environments.

For the purpose of future research, teacher educators must recognize three integral links - "preexisting teacher dispositions" towards "equity pedagogy" profoundly influences the use of "technology for inclusion." Equity signifies not only access to but the operational knowledge of technology in diverse classrooms that can reach the excellence hidden in each child to achieve the goal of Education for All (EFA).

SSLCE focuses on educational equity and technology for inclusion to ensure that the school system of Trinidad and Tobago remains academically competitive with the rest of the world.

\section{References}

[1] Allard, A., and Santoro, N., 2006, Troubling identities: Teacher education students' constructions of class and ethnicity. Cambridge Journal of Education. 36(1), 115129.

[2] Banks, J. A., 2004, Multicultural education. Historical development, dimensions and practice. In J.A. Banks and C.A.M. Banks (Eds.), Handbook of research on multicultural education. 3-29. San Francisco: Jossey Bass.

[3] Bearne, E. (Ed.)., 1996, Differentiation and diversity in the primary school. London: Routledge.

[4] Bell, D., and Thomas, E., 2008, Understanding the Teacher Professional Development Facilitators and Barriers to Serve a Diverse Student Population. Academic
Leadership. The Online Journal. Retrieved January $7^{\text {th }}$, 2010,

http:/www.academicleadership.org/empirical_research/299. shtml.

[5] Collinson, V., Killeavy, M. and Stephenson, H., 1999, Exemplary teachers: Practising an ethic of care in England, Ireland and the United States. Journal for a Just and Caring Education. 5(4), 340-366.

[6] Davis, N. E., 1999, The globalization of education through teacher education with new technologies: A view informed by research through teacher education with new technologies. Educational Technology Review, 1(12), 8-12.

[7] Garmon, M.A., 2004, Changing preservice teachers' attitudes/beliefs about diversity. What are the critical factors? Journal of Teacher Education. 55. 201-213.

[8] Gay, G., 2000, Culturally responsive teaching. Theory, research and practice. New York: Teachers College Press.

[9] Lumley, D. and Bailey, G., 1997, Planning for Technology: A Guidebook for Teachers, Technology Leaders and School Administrators. Bloomington, IN: National Education Service.

[10] Lunddeberg, M., Berglandk M., Klyczek, K. and Hoffman, D., 2003, Using Action Research to Develop Preservice Teachers' Confidence, Knowledge and Beliefs about Technology. The Journal of Interactive Online Learning. 1(4), 1-16.

[11] Marshall, P. L., 2002, Cultural Diversity in our schools. Belmont: CA: Wadsworth Group.

[12] National Council for the Accreditation of Teacher Education, 2002, Professional standards for the accreditation of schools, colleges, and departments of education. Washington, D.C.: Author.

[13] Sandholtz, J., Ringstaff, C. and Dwyer, D., 1997, Teaching with technology: Creating student-centred classrooms. New York: Teachers College Press.

[14] Sleeter, C. E., 1992, Keepers of the American dream: A studyof staff development and multicultural education. Washington, D.C.: Falmer.

[15] Taylor, R. and Wasicsko, M., 2000, The dispositions to teach. Retrieved November $10^{\text {th }}$ 2008, from http:/www.education.eku.edu-Dean-The Dispositions to Teach.pdf.

[16] Tomlinson, C., 2003, Fulfilling the promise of the differentiated classroom. Strategies and tools for responsive teaching.. Alexandria, VA: Association for Supervision and Curriculum Division. 
[17] Trinidad and Tobago Government of (2004). Vision 2020 Draft National Strategic Plan. Port-of-Spain: Ministry of Planning and Development.

[18] Trinidad and Tobago, Government of (2008). National Report on the Development of Education: Inclusive Education Overview. Port-of-Spain, Ministry of Education.

[19] Unesco, 1994, The Salamanca Statement and Framework for Action on Special Needs Education. Paris: Unesco.

[20] UNESCO , 2000, Education for All (EFA). The Dakar Framework for Action. Education for All. Meeting our Collective Communities. Unesco: Paris. 